A consideration of the impact of crowning on the dental pulp, and the special issues involved in crowning root-treated teeth.

- The damaging effects of crown preparation.

- Assessment and preparation of root-treated and non root-treated teeth to minimize endodontic complications.

- Special considerations in the temporisation and restoration of root-treated teeth.

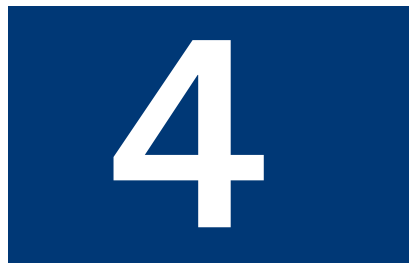

\title{
Crowns and extra-coronal restorations: Endodontic considerations: the pulp, the root-treated tooth and the crown
}

\author{
J. M. Whitworth ${ }^{1}$ A. W. G. Walls ${ }^{2}$ and R. W. Wassell ${ }^{3}$
}

\author{
Endodontic considerations is the fourth in the series on crowns and other extra-coronal restorations. This article focuses \\ strongly on contemporary biological principles, and is not intended to provide a comprehensive review of commercially \\ available materials and techniques. Principles are illustrated in a variety of clinical case scenarios.
}

CROWNS AND EXTRA-CORONAL RESTORATIONS:

1. Changing patterns and the need for quality

2. Materials considerations

3. Pre-operative assessment

4. Endodontic considerations

5. Jaw registration and articulator selection

6. Aesthetic control

7. Cores for teeth with vital pulps

8. Preparations for full veneer crowns

9. Provisional restorations

10. Impression materials and technique

11. Try-in and cementation of crowns

12. Porcelain veneers

13. Resin bonded metal restorations

Senior Lecturer

2Professor,

${ }^{3}$ Senior Lecturer in Restorative Dentistry,

Department of Restorative Dentistry, The Dental School, Framlington Place, Newcastle upon Tyne NE2 4BW

${ }^{*}$ Correspondence to: Dr J. M. Whitworth

E-mail:j.m.whitworth@ncl.ac.uk

\section{Refereed Paper}

(c) British Dental Journal 2002; 192:

315-327
Crowns should not be made without consideration of the teeth which lay the foundations for them. In this article, important principles are outlined for the assessment of root-treated and non root-treated teeth before crowning, avoiding endodontic complications during crown fabrication, and special considerations in the temporisation and restoration of root-treated teeth.

\section{Pulp morbidity in crowned teeth}

Dental pulp is the highly vascular, richly innervated soft tissue structure whose principal role is tooth formation. But even after teeth are erupted into the mouth and fully formed, the dental pulp is not a redundant organ. Pulp tissue retains the important function of supporting its secretory odontoblasts which lay down reparative dentine in defensive response to dental injuries throughout life. There is also some evidence that the pulp may be involved in a pressure-receptive function, limiting the possibility of damaging functional overload on teeth. ${ }^{1}$

If this were not sufficient justification to preserve healthy pulps, then the desire to do patients no harm and to avoid the pain, swelling and suffering which often accompanies the injury and demise of a pulp surely must be.

An insulating coverage of dentine and an impervious layer of enamel protect the pulps of healthy, intact teeth from injury. Crown preparation places the pulp at risk in a number of ways. High speed stripping of hard tissue poses the threat of pulpal overheating, with disturbance of microcirculation, vascular stasis, thrombosis, reduced blood flow and internal bleeding. ${ }^{2}$ It also opens a multitude of dentinal tubules that communicate directly with the pulp. The deeper the dentine is cut, the more permeable it is, ${ }^{3}$ and the more vulnerable the pulp becomes to chemical, physical and microbial irritants. The microbial threat presented by the oral flora is by far the most serious, and is capable of heralding intense inflammatory changes, with micro-abscess formation and progressive pulpal necrosis. ${ }^{4,5}$

Although the pulp shows considerable resilience and is often capable of recovering from irritation, the injuries induced can become significant in the long term. ${ }^{5}$ Scarring as a result of inflammation and repair interferes with the nervous and vascular supply to the tissue $^{6}$ and jeopardises its resistance to further insult. It is important in this respect to recognise that crowns are rarely made for pristine, intact teeth. Rather, they are made to protect and restore teeth which have been damaged by wear, trauma, or cycles of caries and repair. After a lifetime of cumulative insult, crown preparation can be the final straw, bringing pulpal breakdown (Fig. 1a), and the need for root canal treatment. ${ }^{7}$

It is uncertain how many teeth lose vitality as a direct consequence of crown preparation. Bergenholtz and Nyman's ${ }^{8}$ much quoted study showed that $9 \%$ of crowned teeth, compared with only $2 \%$ of uncrowned controls lost vitality during long-term review. None of this was attributable to caries or other obvious causes, but the crowned teeth in this study did have advanced periodontal destruction, and were involved in extensive, cross-arch bridgework. 
Fig. 1a Pulpal breakdown and acute apical periodontitis affecting a recently crowned mandibular first molar

Fig. 1b Root-treatment completed through the crown without serious damage
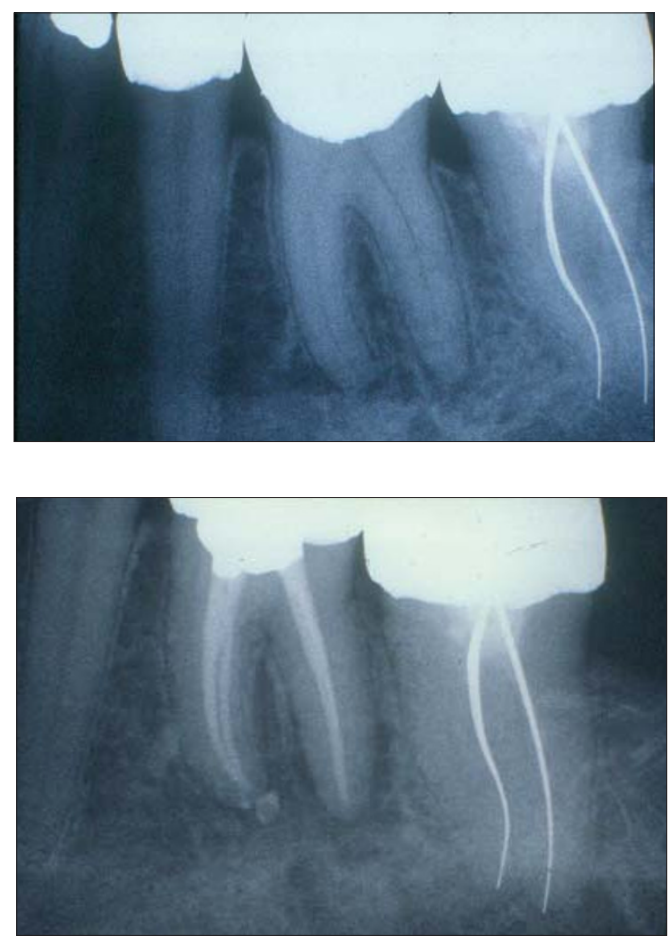

Extrapolation to the case of uncomplicated, single crowns is therefore difficult.

Even higher levels of pulp death were recorded by Felton et al., ${ }^{9}$ where $13.3 \%$ of teeth restored with full coverage crowns, compared with $0.5 \%$ of unrestored controls lost vitality during the 3-30 year review period. But it was not possible to derive from this report how many teeth had suffered further pulpal insult, such as recurrent caries, which may have artificially inflated the adverse effects reported.
A more realistic estimation may be in the order of $4-8 \%$ in the 10 years following active treatment. ${ }^{10-13}$ This estimation does, however, assume that efforts were made to identify and manage all obvious pulpal pathosis before crowns were made; an assumption that cannot always be taken for granted in practice and which increases the likely incidence of unexpected endodontic problems that need attention at a later date.

\section{The dangers of root-treating crowned teeth}

Extra-coronal restorations do not rule out roottreatment or retreatment (Fig. 1b), but it should be noted that working through a crown is always more difficult, and that damage can be done.

Just piercing the glaze of a porcelain crown dramatically reduces its strength, ${ }^{14}$ whilst cutting through a metal ceramic crown can weaken the porcelain bond and predispose to fracture. Vibration can disturb the cement lute of a casting and predispose leakage or loss, whilst rubber-dam clamps may crack and pit cervical porcelain ${ }^{15}$ and occasionally cause a crown to debond.

Once through the crown, the search for the pulp can be hazardous. Metal copings and cores obscure the pulp and prevent its location and assessment from preoperative radiographs. The alignment and rotation of the crown may also not correspond to the underlying tooth, causing loss of orientation and misdirected cutting. Added to this, problems are compounded by limited entry of light and poor visibility.

All of this can leave the operator severely weakening the core and vertical walls of the tooth in search for the pulp chamber and canal

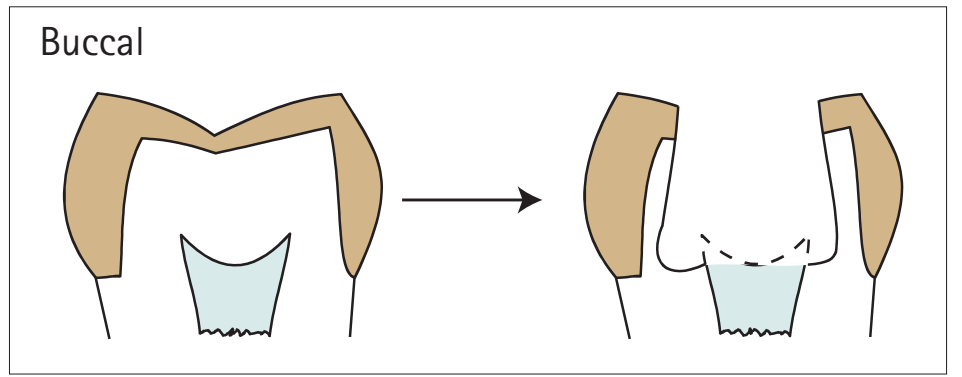

Fig. 2a Overcut and misdirected access through a crown grossly weakens the vertical walls of the preparation

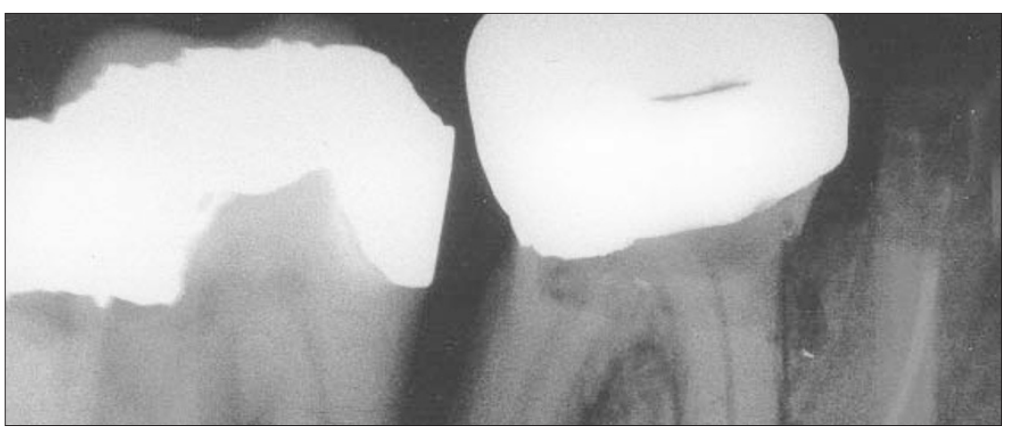

Fig. $2 \mathrm{~b}$ Disorientated by the presence of a crown which had modestly realigned the tooth, the access cavity into this lower molar completely bypassed the pulp chamber to the mesial and lingual. There were no less than five separate perforations 
openings (Fig. 2a). Catastrophic errors such as perforation are also possible (Fig. 2b).

Of equal importance is the damage that can be done to patient confidence and trust if a recently crowned tooth becomes troublesome and has to be accessed or the restoration removed for endodontic treatment. ${ }^{16}$ As the complexity of the crown and bridgework increases, so the consequences become more serious. Replacing a single crown damaged during access is one matter; replacing a large bridge which has suffered irreparable damage to one of its abutments is quite another.

It is certain that a small number of teeth will always develop unexpected endodontic problems after crowning, ${ }^{11}$ but it is also certain that many such instances can be avoided by careful preoperative workup.

\section{PREVENTATIVE ENDONDONTICS - AVOIDING THE AVOIDABLE}

All teeth scheduled to be crowned, whether they are presumed to have healthy pulps or previously root-treated should be thoroughly assessed at the planning stage. In this way, potential endodontic problems can be identified and addressed and future embarrassment and trauma kept to a minimum.

\section{Teeth presumed to have healthy pulps}

Pulps cannot be visualised directly to assess their health. Neither is there a single test which will reliably deliver this information in all circumstances. We rely therefore on a combination of fairly crude methods, including pain history, clinical examination, special tests and radiographs to build a picture of pulp status. All teeth due to be crowned should be tested systematically to give as clear a picture as possible.

\section{Pain history}

A brief pain history reveals areas of the mouth sensitive to hot, cold or sweet, and teeth sensitive to chewing pressure, which require further examination. Review of the case notes may identify teeth with a history of trauma, pulpal exposure or pulpitic symptoms. But this is not enough. Despite textbook accounts of classical toothaches, most injured pulps die quietly, and it is also known that pulpal pain is poorly localised. The absence of reported symptoms is therefore not proof of health, and further examination is needed to identify inflamed and necrotic pulps in need of treatment.

\section{Clinical examination}

Indications of pulp condition may come from the identification of caries, large or leaking restorations, non-carious tooth tissue loss and traumatic injury. Inspection and palpation of soft tissues overlying the apices of teeth to be crowned may reveal signs of endodontic pathosis, including swelling, redness and discharging fistulae. Non-vital teeth may appear slightly darker than their neighbours, and periapically involved teeth may be tender to biting pressure or gentle percussion.

\section{Special tests}

Characteristically, pulpal symptoms are difficult for patients to localise, and require systematic provocation and reproduction to identify the offending tooth with certainty. If sensitivity is reported to hot or cold, the teeth should be challenged with that stimulus. Cold can be applied with an ethyl chloride soaked cotton pledget, though ice sticks or proprietary refrigerants such as Endo-Frost (Reoko) can give a more profound cold challenge to stimulate the pulps of old or heavily restored teeth. Heat can be applied with a stick of warm gutta percha 'temporary stopping', taking care to coat the tooth first with petroleum jelly to prevent the hot material from adhering. Electronic touch and heat instruments used in thermoplastic gutta percha filling techniques can also be used to deliver a known and reproducible thermal challenge.

As a general rule, thermal tests are more discriminating of pulp condition than electrical. ${ }^{17}$ They should be repeated, and contralateral and adjacent teeth tested for reference. An exaggerated and lingering response may indicate irreversible pulpal inflammation, whilst a consistent absence of response may suggest pulp necrosis.

Pulp sensitivity tests are essential in pre-operative assessment, but their results should not be taken in isolation, and should always be interpreted with caution.

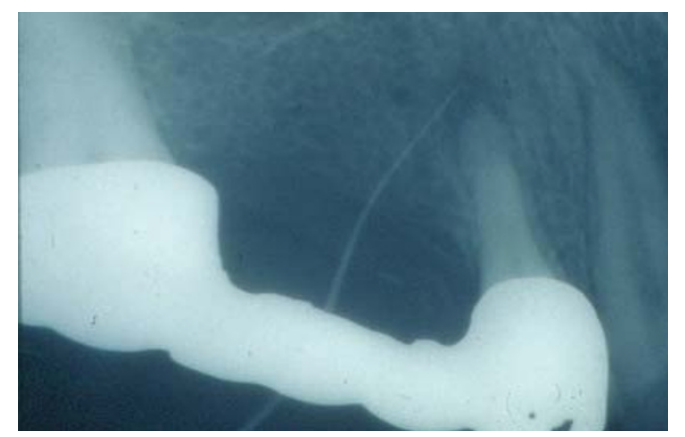

Fig. 3 A gutta percha point inserted into a discharging fistula locates its source at the apex of the premolar bridge abutment

\section{Radiographs}

Periapical radiographs should be of diagnostic quality and taken by a paralleling technique. If there is a discharging fistula, a gutta percha cone size 25 or 30 should be inserted to source the infectious focus (Fig. 3). More than one film, taken at different angles, may be needed to visualise all roots and all root canals, and should be examined for apical and lateral lesions of endodontic origin. If root-treatment is indicated, an assessment should be made of the degree of difficulty this presents, and whether a predictable, quality result is likely.

The size of a healthy, vital pulp should also be noted, especially if the reason for the crown is to realign the tooth. Heavy tooth reduction in such cases may result in embarrassing unexpected pulpal exposure. 


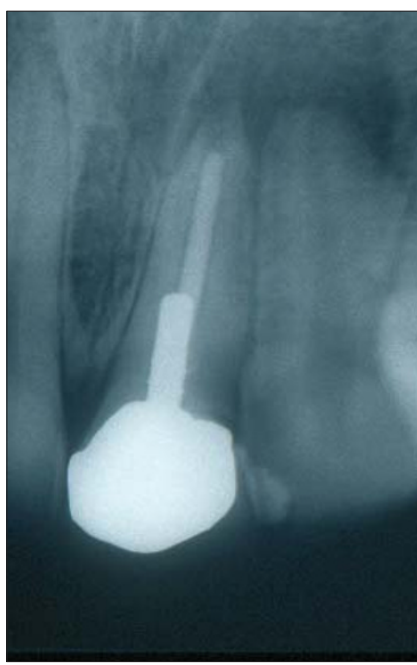

Fig. 4 Pain and swelling associated with a tooth which was recently crowned without revising the unsatisfactory endodontic foundation

Fig. 5 A technically satisfactory root-filling exposed to the mouth through defective restoration margins. Oral microbes will rapidly invade the canal system and compromise the root-treatment. Endodontic retreatment should be considered before a new crown is made

\section{Previously root-treated teeth}

Previously root-treated teeth also need critical appraisal before crowning.

Clinical signs and symptoms of endodontic failure obviously demand endodontic retreatment or surgical revision before a crown is made, but even in the absence of symptoms, technically inadequate, short or poorly condensed root fillings (Fig. 4) do not represent predictable foundations and should be revised. Even if the resultant root filling is not better extended, recleaning the canal system can only improve the internal environment of the tooth, and make a better foundation for restoration.

A further group of unreliable teeth is those where the root filling has been open to the mouth through defective restoration margins or restoration loss (Fig. 5). Saliva and micro-organisms migrate quickly alongside exposed root fillings, ${ }^{18}$ and whilst firm rules are difficult to make, it is probably wise to revise all root fillings that have been exposed to the mouth for more than a month, even if they appear technically satisfactory on radiographs. The appearance of the film in such cases denies the biological status of the canal system.

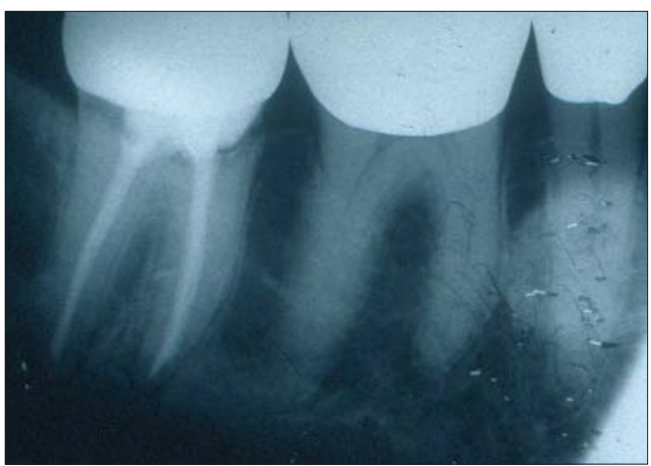

Treatment planning and guidelines

Teeth identified as having necrotic pulps, or showing signs of irreversible pulpal inflammation should be root-treated before crowns are prepared. Elective root-canal treatment should also be planned for teeth whose pulps are at serious risk of exposure during crown preparation, and for teeth that cannot be restored without using the pulp chamber and root canals for retention and support. Pulps accidentally exposed during crown preparation should not be capped; root canal therapy should proceed.

Technically inadequate root fillings, and root fillings which have been exposed to the mouth, should be replaced before crowning. This option is always preferable to retreatment or corrective surgery after the event. Decisiveness is also called for in the case of teeth which are unrestorable, or which are of very poor prognosis. Procrastination rarely rewards the practitioner and such teeth should be planned for extraction.

If there is doubt in a complex case over diagnosis, or the ability of the practitioner to lay a reliable endodontic foundation, referral for a specialist opinion should be considered.

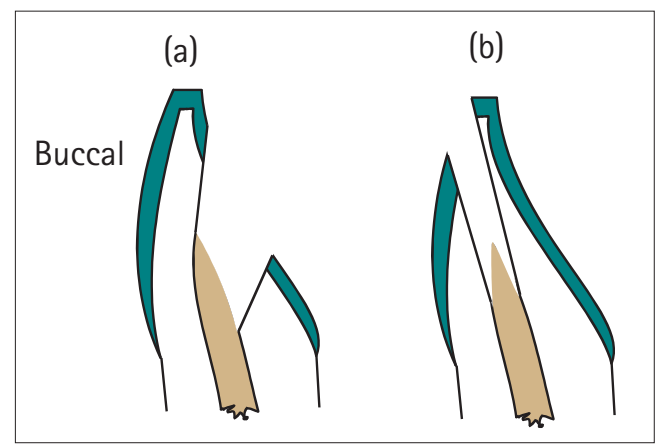

Fig. 6 a) Conventional access does not compromise aesthetics, but sacrifices much lingual tissue. b) Labial/incisal access preserves tissue in teeth scheduled to be crowned. The access can be aesthetically temporised with composite resin

Detailed accounts of contemporary roottreatment and retreatment techniques are beyond the scope of this article, and readers are referred to standard texts. ${ }^{19,20}$ However, important guiding principles should be stated. Roottreatment or retreatment should sacrifice a minimum of structurally important tooth tissue, which is compatible with quality care. Access cavities should not be over-cut and root canals should not be over-flared; to do so simply risks weakening the tooth further. Anterior teeth may in fact be best accessed though the incisal and labial surfaces to preserve tissue ${ }^{21}$ (Fig. 6).

Posterior teeth may be reduced out of occlusion at the start of treatment to minimise the risk from damaging wedging forces splitting the accessed tooth, and the additional support of a well-fitting orthodontic band cemented with glass-ionomer cement may be considered for badly broken-down and vulnerable teeth (Fig. 7).

After root-treatment is complete, provisional restorations should be in place for the minimum time possible and should seal against the ingress of saliva and micro-organisms to the canal system, which will predispose failure. Temporary restorations in place for any time should also provide the necessary protection and support to prevent tooth fracture. Further consideration will be given later to the temporisation and restoration of root-treated teeth.

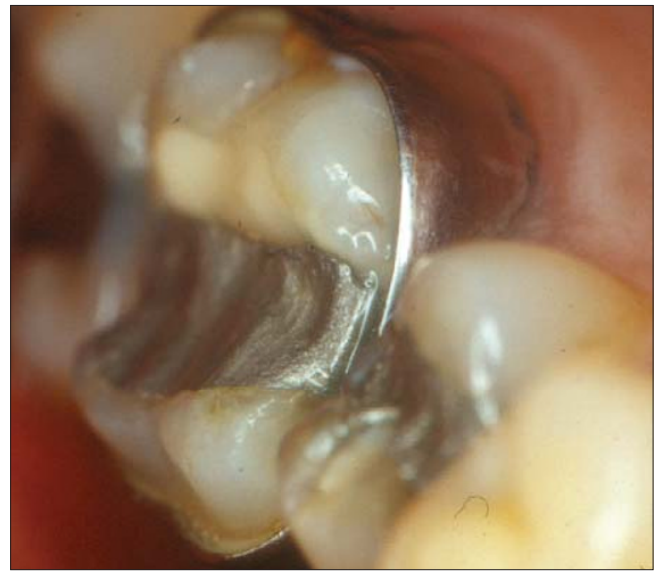

Fig. 7 A well-fitting orthodontic band provides support and protection for a vulnerable posterior tooth 


\section{MINIMISING DAMAGE TO TEETH WITH HEALTHY PULPS}

Having now identified and treated those teeth with inflamed, necrotic or at risk pulps, the remaining teeth should be treated with all respect to preserve their pulps in health. Frictional heat generated during crown preparation should be strictly controlled. Although dentine is a good thermal insulator, damaging rises in temperature can occur, especially in preparations involving substantial tissue removal. High volume, well focused water-cooling should be used at all times, ${ }^{22,23}$ and cutting strokes should be intermittent and light.

Open dentinal tubules should also be managed with care and respect. Cut dentine should not be over-dried with the 3 in 1 syringe, and smear plugs should not be removed by the careless application of acidic astringents used in gingival haemorrhage control.

Bacteria and their metabolic by-products are the greatest danger to pulp health, ${ }^{24,25}$ and it behoves the practitioner to ensure that temporary and permanent crowns fit accurately and provide the best possible marginal seal. The pre-sealing of dentine with a resin-bonding agent may be a means of reducing dentine permeability and enhancing pulp protection, ${ }^{26}$ though there are few published data to date which specifically demonstrate the effectiveness of this action in preserving the pulps of crown-prepared teeth.

\section{RESTORATION OF THE ROOT-TREATED TOOTH}

\section{General considerations}

Root-treated teeth are in a vulnerable state until they are permanently restored.

The risks they face fall into two major categories:

1. Fracture of remaining tooth tissue

2. Reinfection of the root canal from the mouth

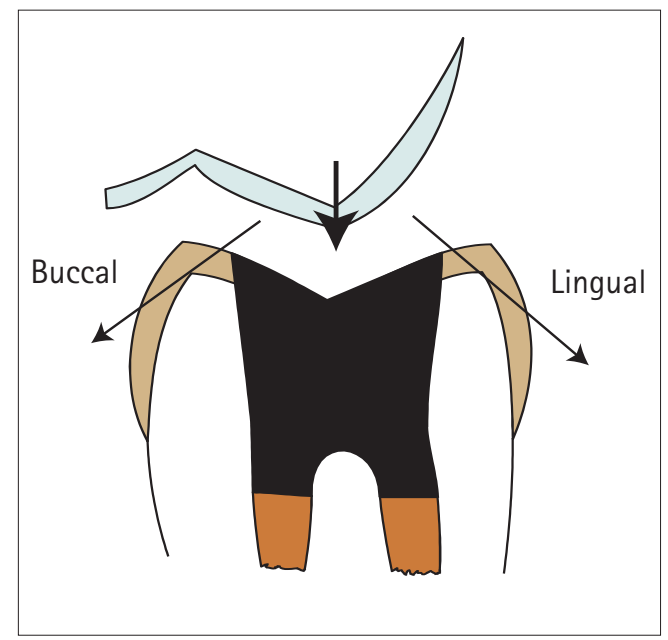

These two considerations underpin the approach to temporising and restoring all roottreated teeth.

\section{Protecting root-treated teeth from fracture}

It is widely held that root-treated teeth are brittle. Historically, this has been attributed to desiccation, or other physical changes in the dentine of pulpless teeth, which reduce its toughness.

More recently, it has been recognised that the key change is the loss of structural tissue which is capable of holding the tooth together under functional load. This is especially so for posterior teeth, where wedging forces come to bear (Fig. 8). Conservative access preparation in an otherwise sound tooth may not be especially damaging, but endodontic access in combination with the earlier loss of one or both marginal ridges leaves the tooth at serious risk, even if it was reduced from direct occlusal contact before endodontic treatment began.

For this reason, some form of cuspal coverage should always be provided for root-treated posterior teeth, ${ }^{27}$ unless the endodontic access is the
Fig. 8 Wedging forces on the unprotected cuspal slopes of a root-treated posterior tooth (a)

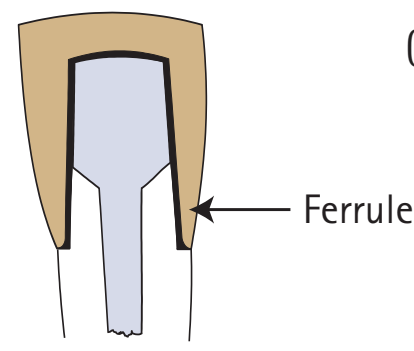

(b)

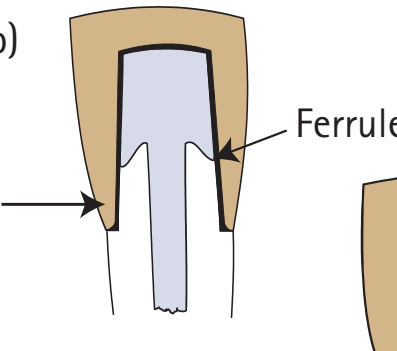

(d)

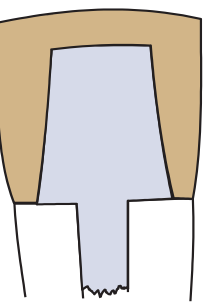

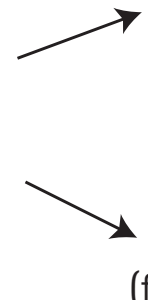

(f) (e)
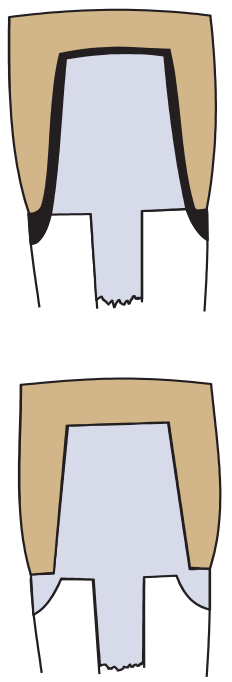

Fig. 9 The development of protective ferrules for anterior teeth: a) Moderate loss of tooth tissue - the post and core provide no protection, a ferrule is provided by the crown; b) Moderate loss of tooth tissue - bevelling of the residual tooth tissue allows the core as well as the crown to provide protective ferrules; c) Decoronated, root-treated anterior tooth which is vulnerable to fracture and requires protection; d) No protective ferrule provided by the core, or by the crown; e) No protection provided by the core, but the crown extends onto tooth and provides a protective ferrule; and f) Protective ferrule provided by a cast post and diaphragm 
Figure 10 a) Wide and tapered root canal. b) Preparation for a parallel post removes more tissue and weakens the root further. Stresses are also concentrated at the sharp angles of the post terminus. c) Custom cast metal post requires little or no further loss of tissue
Fig. 11 Canal entrances and pulp chamber anatomy used to retain an all amalgam core in a molar. Composite resin may be used in a similar way for anterior teeth
Fig. 12 a) Fractured and roottreated incisor to be restored with a post retained crown. b) Rooftop preparation damagingly removes all remaining coronal tooth tissue, and may compromise the ability to create a protective ferrule. c) Conservative preparation preserves tooth tissue, lengthens the post, and allows the development of protective ferrules
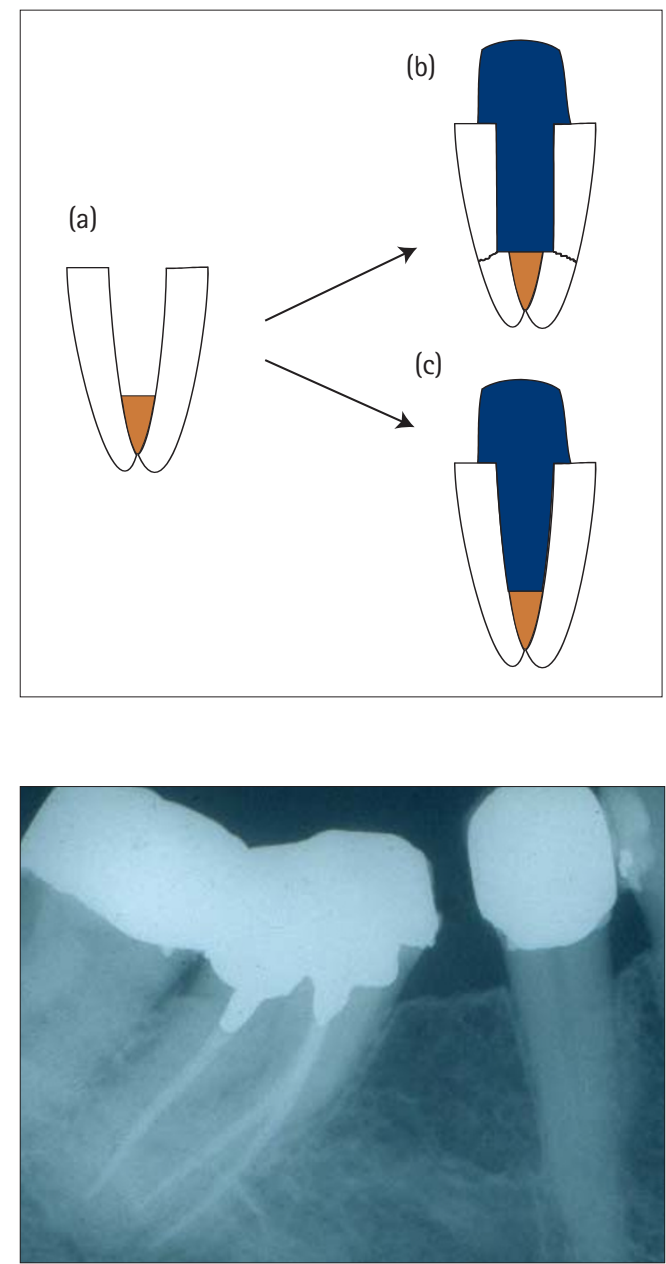

only coronal tissue loss, and there are no damaging functional or parafunctional loads on the tooth.

Incisors and canines are spared the wedging cuspal deflections of posterior teeth, but they too can suffer longitudinal fracture if significant tooth tissue has been lost, and a protective ferrule is not incorporated into the coronal restoration. A ferrule is a band of metal which totally encircles the tooth, extending 1-2 mm onto sound tooth tissue to guard against longitudinal fracture. ${ }^{28}$ Figure 9 shows examples of ferrules for moderately and severely broken down ante-

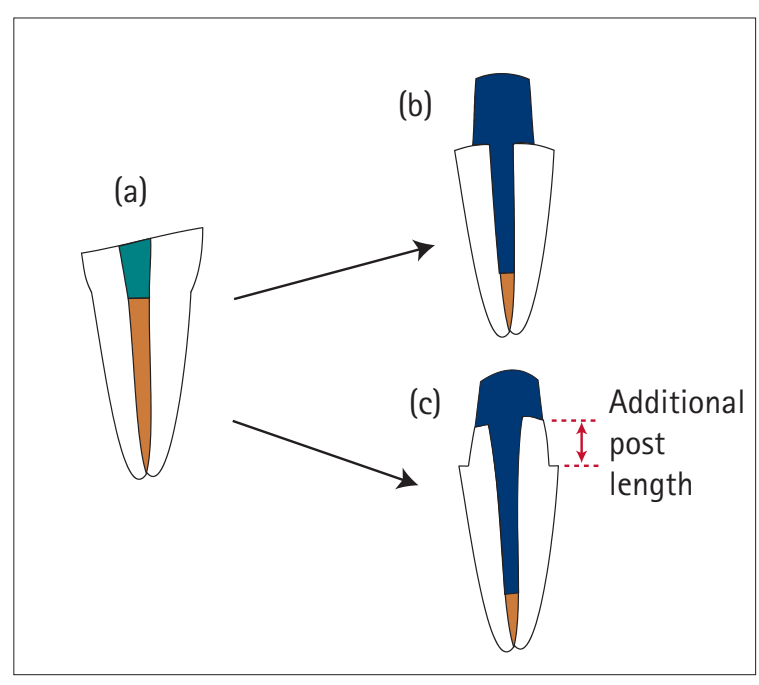

rior teeth. For such teeth ferrules should be incorporated as routine.

\section{Posts: a means of protecting teeth from}

fracture?

Another popular misconception is that the cementation of a metallic post in a root-treated tooth provides reinforcement. In reality, the post offers no reinforcement, and dentine removal to accommodate it may in fact weaken the tooth further and create an area of stress concentration at the terminus of the post channel (Fig. 10).

The chief function of a post is to retain the core. If adequate retention for the core can be derived from the use of natural undercuts in the pulp chamber and canal entrances (Fig. 11), then a post should not be used.

If a post really is required, then consideration should be given to how it can provide retention for the core without weakening or stressing the tooth, or compromising the effectiveness of the root filling.

Practitioners are not short of choice in post selection, and it is certainly beyond the scope of this article to consider the many systems available in any detail. A review of commercially available systems by Edmunds and Dummer ${ }^{29-32}$ ran to no less than four articles, and new systems continue to appear.

The literature contains many in vitro reports of post performance and failure characteristics, but as in many other areas of dentistry, wellcontrolled clinical studies are few and far between. Objective judgements cannot therefore be made on the performance of many of the available post systems, though certain principal considerations can be derived.

It is likely that many post systems will provide satisfactory retention for the coronal restoration, but the potential cost of enhancing retention should be considered. Dentists should perhaps focus less on factors which maximise retention and more on factors that affect resistance to root fracture, ${ }^{27}$ ie the preservation and protection of tooth tissue, and the avoidance of stressing restoration components.

\section{Avoiding problems with posts}

\section{Post length}

There is little doubt that long posts are more retentive than short posts. Endodontic posts should therefore be as long as possible, and it is important to note that this is achieved not only by extending the post apically, but also by preserving tooth tissue coronally (Fig. 12). There is no place for the decoronating 'rooftop' preparation in the restoration of root-filled teeth. This is particularly so when evidence suggests that at least 4-5 $\mathrm{mm}$ of gutta percha should remain apically to ensure that the seal of the root filling is not compromised. ${ }^{11,33}$

Retaining coronal dentine also allows for wrap-around coverage by the subsequent crown, which provides the essential 'ferrule effect' discussed earlier (Fig. 12c). 


\section{Post shape}

All other factors being equal, parallel-sided posts, such as the Parapost (Fig. 13) are more retentive than tapered posts. ${ }^{34}$ However, the preparation of a parallel-sided post channel, and subsequent cementation of a square-ended parallel post may produce increased stress in the narrow and tapering root-end ${ }^{35}$ (Fig. 14a) and predispose to root fracture. Systems, which are bevelled apically may therefore be preferred (Fig. 14b). But once again, the preservation of tooth tissue is important to the long-term integrity of the tooth, and tissue should not be sacrificed in order to create a parallel-sided post channel if a well-adapted tapered post can be placed with less sacrifice of dentine.

Tapered posts such as the PD system have a good record of clinical success. ${ }^{36}$ Concerns have often been raised over the generation of wedging stresses by tapered (including customised cast) posts, and the tendency to promote root fracture. However, such forces are not active in the same way as those generated by self-tapping screw systems, and it may be that many cases of root fracture associated with tapered posts reflect the type of cases in which such posts are often used, ie the wide, thin-walled tapered canal. Again, the importance of providing a protective coronal ferrule cannot be overemphasised.

In their study of parallel versus tapered post systems, Torbjornet et al. ${ }^{34}$ noted that in fact the type of post may be of minimal importance to the risk of root fracture if the tooth is covered by a complete crown with a good ferrule effect at the crown margin area. Their comments were not, however, directed to posts involving active methods of retention.

Customised cast posts are especially versatile and can often be fabricated with the minimum of additional canal preparation. Such posts have a strong history of clinical success $^{28,37}$ especially once again when a coronal ferrule is provided.

In summary, parallel-sided posts are preferred to tapered posts, but each case should be carefully considered on its merits, and dentine should not be unnecessarily sacrificed to dogmatically satisfy the desire to place a moderately more retentive parallel post.

\section{Surface characteristics: threaded versus non-threaded posts}

There is little doubt from the literature that threaded post systems offer the maximum mechanical retention. But the retention they provide is often by active engagement of elastic dentine, producing stress concentration around the threads, and increasing the risk of root fracture. $^{38}$ This is especially so if posts are selftapping, and is amplified if the post also has a wedge-like, tapered design.

Popular commercial threaded posts include:

- Radix Anker (Fig. 15)

- Dentatus (Fig. 16)

- Kurer Anchor (Fig. 17)

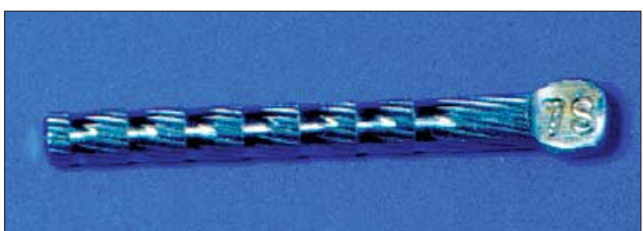

Fig. 13 Parapost - parallel, serrated post

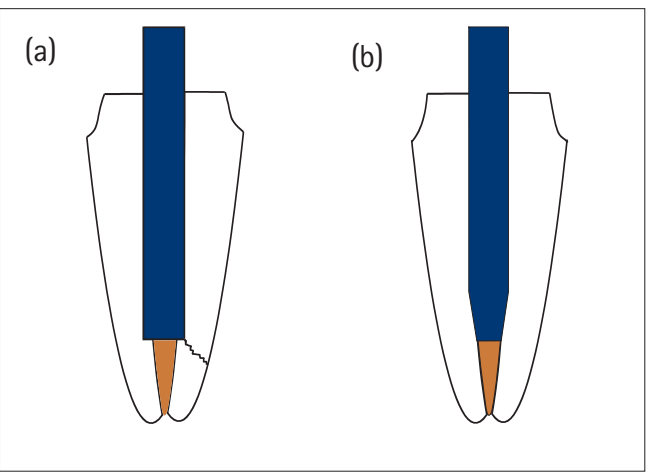

Fig. 14 a) Stress concentration at the base of a parallel post preparation. b) Reduced stress concentration with a chamfered tip

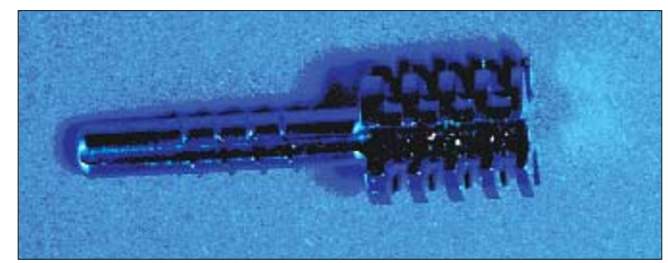

Fig. 15: Radix Anker - parallel, self-tapping or pre-tapped post

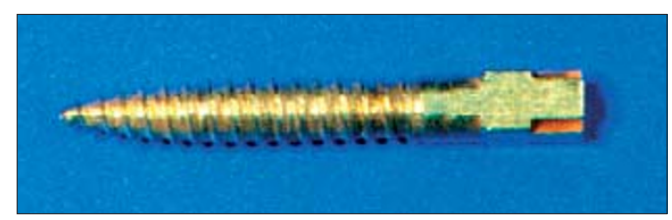

Fig. 16 Dentatus screw - tapered, self-tapping post

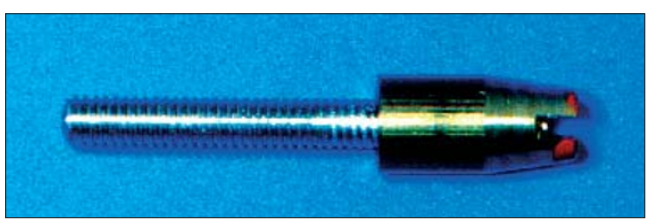

Fig. 17 Kurer Anchor - parallel, threaded post for which the root canal is pre-tapped
Concerns have been expressed about all threaded post systems, and it is notable that most manufacturers now recommend that the post is used first to cut a thread, and is then removed and reinserted with cement, or is simply derotated a quarter turn to reduce stresses which are generated during initial insertion. The Kurer post system, in which the canal is first tapped before post insertion, is probably the least stressing of threaded post systems. Another method of limiting stress is seen in the Flexipost, which incorporates a split-pin mechanism, the split pin collapsing upon itself as the post is inserted to reduce pressure on the canal walls. ${ }^{39}$

Generally speaking, threaded posts are not preferred and Meta analysis of the limited clinical evidence available suggests that their performance is inferior to that of customised cast posts. ${ }^{37}$ If enhanced retention is required in a special situation, then threaded posts are no longer the only option. Increasingly, resin-bonding agents may be employed with serrated, and preferably sandblasted metal or fibre posts, reducing the potential 
for stress, and enhancing the possibility of developing an hermetic coronal seal. ${ }^{28}$

\section{Minimising danger during post space preparation}

Ideally, post space preparation is completed at the appointment when the root canal is filled. At this time, the practitioner is most familiar with the canal system and reference points. He is also able to make post space with the rubber dam in place to minimise microbial entry, and can further condense the apical segment of the root filling after the coronal gutta percha has been removed. Gutta percha removal and post channel preparation should not be undertaken in a single act with the aggressive end-cutting twist drills provided with proprietary post systems. To do so is to risk losing alignment and perforating the root for the sake of a few seconds of time. Gutta percha should first be removed to the predetermined length using burs with non-cutting tips (eg Gates Glidden) or with hot instruments before the channel is shaped and enlarged progressively with measured twist drills.

Guarding against coronal microleakage

Coronal microleakage is a major cause of endodontic failure. ${ }^{40}$ Saliva and organisms from the mouth migrate rapidly alongside poorly adapted restorations and even root fillings which appear well condensed. ${ }^{18}$ The periradicular tissues will be inflamed by such reinfection and the reactivation of micro-organisms lying dormant after initial treatment. A well sealing coronal restoration is critical therefore to endodontic success, and it is again stressed that this applies as strongly to temporary restorations as it does to permanent ones. Posterior teeth can be temporised with cuspal-coverage amalgam restorations, which will prove durable and well sealing for many months or years. But the same cannot be said for anterior temporary post crowns, which should be in place for the minimum time possible.

Restorations should be well adapted, and every use should be made of modern adhesive systems in an effort to control salivary entry.

\section{TREATMENT GUIDELINES}

In summary, the guiding principles in restoring root-treated teeth are:

1. Preserve as much tooth tissue as possible

2. If a post is needed make sure it is long enough to be retentive and sufficiently strong to resist distortion

3. Avoid twist drills for the removal of gutta percha

4. Avoid active restorations or restoration components which induce internal stresses

5. Provide the necessary coronal coverage for protection

6. Strive for the best possible fluid and bacteriatight seal

These principles will now be illustrated for a variety of restorative scenarios.

\section{Minimal loss of coronal tissue}

Incisors and canines which have lost tissue during access preparation, in addition to tissue loss caused by caries in one or both proximal surfaces can often be restored to satisfactory long-term function and aesthetics with dentine and enamel-bonded composite resin. Gutta percha should be cleared from the interior of the crown with hot instruments or Gates Glidden drills. Powerful organic solvents such as chloroform or halothane are not recommended in post channel preparation, as it is impossible to control their advance into the root canal where they can rapidly dissolve gutta percha and sealer at a deeper level than anticipated. All traces of sealer should be removed from the coronal tissues to prevent later discolouration. Concerns have been expressed about zinc oxide-eugenol sealers in particular, traces of which may interfere with the polymerisation of restorative resins. Alcohol rapidly sequesters excess eugenol and is not known to threaten the integrity of gutta percha root fillings. It may be wise to rinse the pulp chamber with alcohol to remove traces of eugenol before attempting to bond. ${ }^{41}$

Premolars and molars with only minimal access cavities and no other coronal tissue loss can be restored with amalgam or composite resin in combination with a resin bonding system to enhance the marginal seal. The restorative material should be extended $2-3 \mathrm{~mm}$ into canal entrances by carefully removing root filling material with hot instruments or Gates Glidden drills. However, large Gates should not be extended deeply into canals with the risk of unnecessary dentine removal, and even strip perforation. The first increments of core material should be packed with a long, narrow plugger (eg Mortensen Condenser) to ensure good adaptation into these retentive features.

\section{Moderate loss of tooth tissue}

Advances in bonding technology and improvements in the physical and aesthetic properties of composite resins continue to increase the potential for simple, plastic restoration of anterior teeth. Depending upon aesthetic and functional demands, root-treated teeth with proximal and incisal tissue loss, in addition to the access cavity may often be restored without the need for a crown. Bonding composite resin soon after completion of the root filling has the added advantage of securing an early, hermetic seal against coronal microleakage.

It is impossible in this context to lay down firm rules on the precise degree of tissue loss that can be successfully restored in this nondestructive way. But it should also be noted that teeth restored with simple plastic restorations can always be revisited at a later stage for a more advanced and destructive restoration if the need arises.

Anterior teeth, which have some coronal tissue remaining, but where this is considered insufficient for long-term restoration with composite resin, either on functional or aesthetic 
grounds, require core build-up and a crown. The core may not always need a post for retention.

Gutta percha and sealer are first cleared from the crown and coronal 2-3 $\mathrm{mm}$ of the root canal. The remaining coronal tooth tissue is then prepared to receive a crown. Under no circumstances should the tooth be decoronated to create a 'rooftop' preparation (Fig.12a, b). Weak, undermined coronal tissue and spurs of tissue, which are taller than they are wide, should be reduced and the remaining, well-supported tissue bevelled. Every effort should be made to preserve as much coronal tissue as possible. If there is adequate retention and support available for the core material, then dentine-bonded composite is cured into the chamber and extended to complete the preparation coronally.

If tissue loss is more severe, then a post is required (Fig. 12c). This may either be cast, or prefabricated. Gutta percha is removed from the canal, leaving 4-5 $\mathrm{mm}$ of filling material apically. An initial path is made with hot instruments, or with Gates Glidden drills, numbers 2 and 3, which should be running at the maximum speed achievable with the slow speed handpiece to generate frictional heat which will soften the gutta percha and ease its removal without disturbing the apical root filling. ${ }^{42}$ Having created a path, twist drills appropriate to the post system selected are used to enlarge and shape the channel. Excessive dentine should not be removed to accommodate snugly a preformed parallel post in a flared canal. In this situation, a tapered or customised cast post or a fibre post is often preferred.

Impressions may then be taken for the production of an indirectly constructed casting, or a direct pattern fabricated in the mouth. Metal castings have the advantage that features can be built in to provide a protective ferrule, and that they can be customised to minimise the need for dentine removal. The chief disadvantage of this approach is that the tooth will need temporisation with a temporary post crown, which is unlikely to provide an hermetic coronal seal during the time required to fabricate the post. ${ }^{43}$

For this reason, it may be preferable to restore the tooth immediately with a prefabricated post, and composite core. ${ }^{43,44}$ An immediate, and permanent coronal seal is then secured. This benefit should be balanced in heavy loading situations with consideration of the strength of the core and the post-core interface. However the devel- opment of a ferrule by extending crown margins well onto sound tooth tissue should minimise the physical demands on the composite core. Such extension may be subgingival or involve a crown lengthening procedure or forced eruption to obtain supragingival margins.

Posterior teeth, which have lost one or both marginal ridges in addition to tooth loss for endodontic access, require cuspal coverage. Amalgam or composite cores can again often be retained without the need for posts. If a post is considered necessary, it should usually be placed in the straightest and most bulky root, commonly the distal in lower molars, and the palatal in upper molars. Premolar roots should be judged on their merits. Even if a post is placed, rootfilling materials should always be removed from the entrances of other canals to provide supplementary retention for the core, and resistance to rotational torque.

A cuspal coverage restoration can then be prepared which fits the functional and aesthetic demands of the situation. This may be as conservative as a cast metal onlay, or three-quarter crown, or as extensive as a full-coverage metal or ceramo-metal crown (Fig. 18). Extracoronal restorations should be extended at least 1-2 mm onto sound tooth tissue to provide allenveloping protection against fracture of the underlying tooth.

Adhesively retained plastic restorations cannot be relied upon as long-term internal splints. If there is no plan to crown a weakened posterior tooth, either because the root-treatment is on probation, or for financial reasons, then physical cuspal coverage and protection must be provided by the core material. Cusps adjacent to lost marginal ridges should be reduced in height by $3 \mathrm{~mm}$ and overlaid with dentine bonded amalgam or composite resin. Such restorations can provide cost-effective, durable service for many years. ${ }^{45}$

\section{Extensive loss of tooth tissue}

Teeth with little or no coronal tissue remaining require special measures to provide a protective ferrule. Again, surgical crown lengthening or forced eruption may be needed to allow the placement of restoration margins on sound tissue.

Anterior teeth may be prepared to receive a cast metal post and diaphragm (Fig. 19), with extension of the metal casting over the bevelled or chamfered margins of the root-face to provide

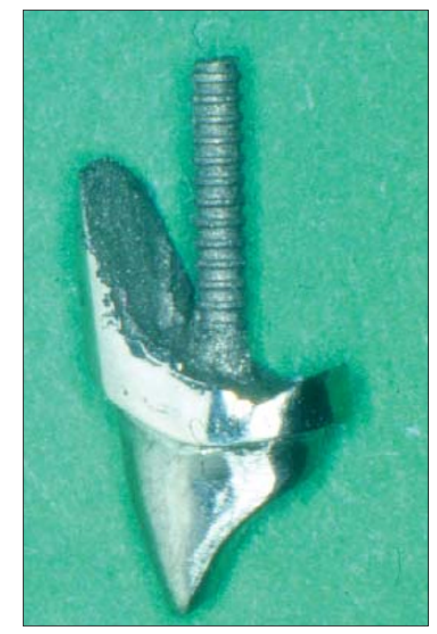

Fig. 19 Cast post and core with a diaphragm to cover and support a damaged incisor root (a)

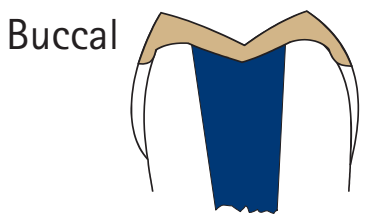

(b)

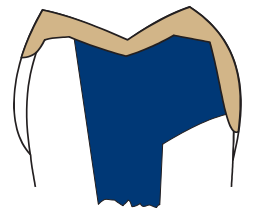

(c)

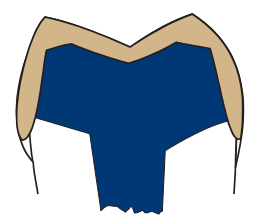

Fig. 18 Cuspal protection and development of protective ferrules for posterior teeth with varying amounts of tissue loss: a) Simple metal onlay, b) Three-quarter crown, c) Full coverage crown 
(a)

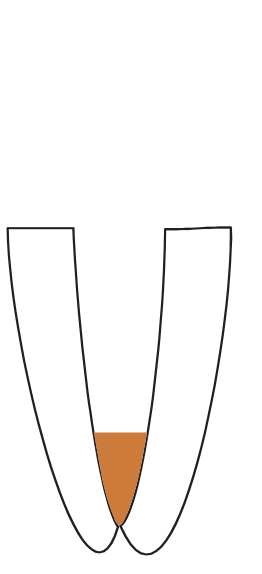

(c)

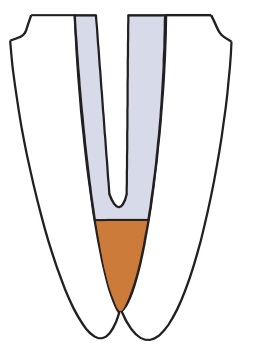

(b)

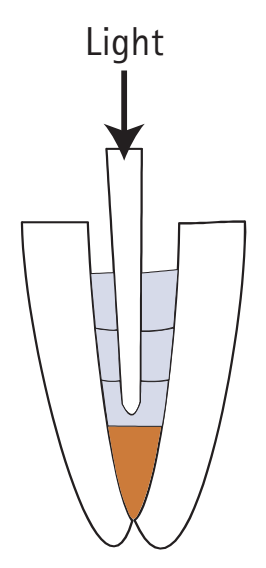

(d)

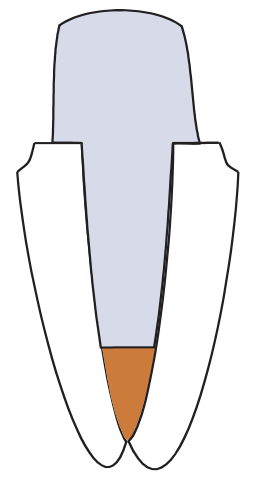

Fig. 20 Rehabilitation of a severely weakened tooth by relining with composite resin: a) Hollowed-out, fragile root; b) Incremental additions of composite cured with a light-transmitting post; c) Space for a conventional post within the composite resin 'reline'. Tooth margins prepared for the crown to provide a ferrule; and d) Continuous composite post and core takes advantage of the materials cohesive strength in thick section. Tooth margins prepared for the crown to provide a ferrule

Fig. 21 a) Metal post and core for a decoronated posterior tooth. The margins of the preparation are chamfered to provide a ferrule. The metal casting contains two short posts for the buccal roots. A separate wrought post will be inserted through it into the palatal root. b) The casting in place, with the wrought, parallel post cemented through it and into the palatal root
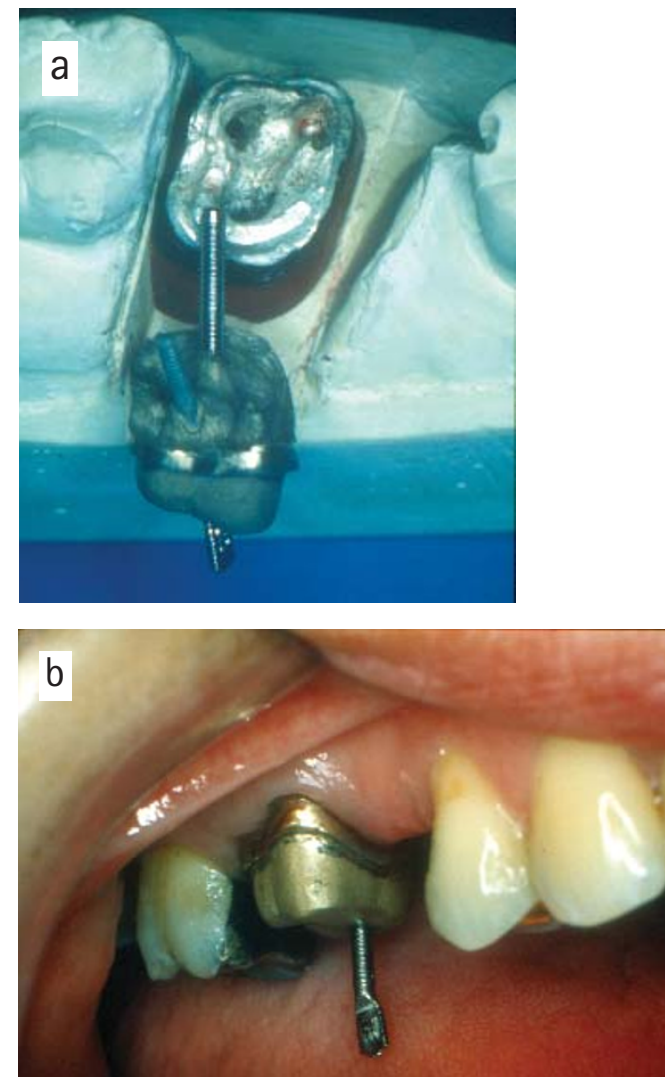

an effective ferrule. Alternatively, a conventional cast or prefabricated post and core may be placed, before constructing a crown with a metal collar extending 1-2 $\mathrm{mm}$ onto tooth tissue to afford the necessary protection.

Immature or hollowed-out roots can present special problems for rehabilitation. One method involves packing dentine bonded composite resin into the widened canal, and curing it in place with light-transmitting posts to effectively reline and internally splint the root (Fig. 20). ${ }^{46}$ Alternatively, self-curing composite can be used. Conventional or fibre ${ }^{44}$ posts may then be cemented into the 'relined' root before coronal core build-up, or advantage taken of the cohesive strength of composite in thick section to build a continuous mass of composite forming the post and core. The final crown should again incorporate a ferrule extending well onto sound tooth tissue for protection.

Posterior teeth which cannot be built up with post and adhesive-retained plastic materials may occasionally require the fabrication of a sectional casting. These restorations are difficult, exacting, and costly to manufacture and are testament to the engineering skills of practitioner and technician. Separate post and core elements with different paths of insertion that link on placement, or a single core unit with channels for multiple post placements at different angles may be manufactured (Fig. 21).

The extracoronal restoration should again be extended onto sound tooth tissue to provide a supporting ferrule for the underlying tooth.

In conclusion:

1. All teeth to be crowned should be carefully assessed as to their pulpal and endodontic status, and reliable foundations laid

2. Teeth with healthy pulps should be prepared and temporised with due care to preserve pulpal health

3. Root-treated teeth are at risk of fracture and of coronal microleakage. Control of these factors should underpin the design of all temporary and permanent restorations for such teeth.

1. Randlow K, Glanz P O. On cantilever loading of vital and non vital teeth: an experimental clinical study. Acta Odontol Scand 1986; 44: 271-277.

2. Zach L. Pulp lability and repair: effect of restorative procedures. Oral Surg 1972; 33: 111-121.

3. Pashley D H. Clinical considerations of microleakage. J Endod 1990; 16: 70-77.

4. Cox CF, Subay R K, Suzuki S, Suzuki S H, Ostro E. Biocompatibility of various dental materials: pulp healing with a surface seal. Int J Periodont Rest Dent 1996; 16: 241-251.

5. Bergenholtz $\mathrm{G}$. latrogenic injury to the pulp in dental procedures: aspects of pathogenesis, management and preventive measures. Int Dent J 1991:41: 99-110.

6. Seltzer S, Bender I B. The Dental Pulp. 3rd Edition. pp324-348. Philadelphia: Lippincott, 1984.

7. Abou-Rass M. The stressed pulp condition: An endodonticrestorative diagnostic concept. J Prosthet Dent 1986; 48: 264-267.

8. Bergenholtz G, Nyman S. Endodontic complications following periodontal and prosthetic treatment of patients with advanced periodontal disease. J Periodonto/ 1984; 55: 63-68.

9. Felton D, Madison S, Kanoy E, Kantor M, Maryniuk G. Long 
term effects of crown preparation on pulp vitality. J Dent Res 1989; 68 (special issue): 1009

10. Landolt A, Lang N P. Erfolg und misserfolg be extensionsbrucken. Schweiz Monat Zahnmed 1988; 98: 239-44. [German with English abstract]

11. Reichen-Graden S, Lang N P. Periodontal and pulpal conditions of abutment teeth. Schweiz MonatZahnmed 1989; 99: 1381-1385.

12. Gonzalez G, Wier D J, Helm F, Marshall S J, Walker L, Stoffer W. et al. Incidence of endodontic treatment in teeth with full coverage restorations. J Dent Res 1991; 70 (special issue): 446.

13. Valderhaug J, Jokstad A, Ambjornsen E, Norheim P W. Assessment of the periapical and clinical status of crowned teeth over 25 years. J Dent 1997; 25: 97-105.

14. McLean J W. The Science and Art of Dental Materials. Vol. 1. p 59. Chicago: Quintessence, 1979.

15. Madison $S$, Jordan R D, Krell KV. The effect of rubber dam retainers on porcelain fused-to-metal restorations. J Endod 1986; 12: 183-186.

16. Dental Protection. Annual Report of the Board 1996; 8: 22

17. Cohen S. In Cohen S, Burns R C. (eds). Pathways of the Pulp. 6th edn. pp2-24. St Louis: Mosby, 1994.

18. Khayat A, Lee S J, Torabinejad M. Human saliva penetration of coronally unsealed obturated root canals. J Endod 1993; 19: $458-461$

19. Walton R, Torabinejad M. Principles and Practice of Endodontics. 2nd edn. Baltimore: Saunders, 1996.

20. Pitt-Ford T R. Harty's Endodontics in Clinical Practice. 4th edn. Oxford: Wright, 1997.

21. Clements R E, Gilboe D B. Labial endodontic access opening for mandibular incisors: Endodontic and restorative considerations. J Can Dent Assoc 1991; 57: 587-589.

22. Langeland $K$, Langeland LK. Pulp reactions to cavity and crown preparation. Aust Dent J 1970; 15: 261-276.

23. Langeland $K$, Langeland LK. Cutting procedures with minimized trauma. J Am Dent Assoc 1968; 76: 991-1005.

24. Bergenholtz G, Cox C, Loesche W J, Syed S A. Bacterial leakage around dental restorations: its effect on the dental pulp. J Oral Pathol 1982; 11: 439-450.

25. Goldman M, Laosonthorn P, White R R. Microleakage: full crowns and the dental pulp. J Endod 1992; 18: 473-475.

26. Cox CF, Suzuki S. Re-evaluating pulp protection: Calcium hydroxide liners vs. cohesive hybridization. J Am Dent Assoc 1994; 125: 823-831.

27. Sorensen J A, Martinoff J T. Intracoronal reinforcement and coronal coverage: a study of endodontically treated teeth. J Prosthet Dent 1984; 51: 781-784.

28. Morgano S M. Restoration of pulpless teeth: an application of traditional principles in present and future contexts. $J$ Prosth Dent 1996; 75: 375-380.

29. Edmunds D H, Dummer PM H. Root canal retained restorations: 1. General considerations and custom-made cast posts and cores. Dent Update 1990; June: 183-188.

30. Dummer P M H, Edmunds D H. Root canal retained restorations: 2. Prefabricated post and core systems (i) Non-threaded posts. Dent Update 1990; July/August: 244-249.

31. Dummer P M H, Edmunds D H. Root canal retained restorations: 2. Prefabricated post and core systems (ii) Threaded posts. Dent Update 1990; September: 286-289.

32. Edmunds D H, Dummer PM H. Root canal retained restorations revisited. Dent Update 1993; January/February: 14-19.

33. de Cleen M J H. The relationship between the root canal filling and post space preparation. Int Endod J 1993; 26: 53-58.

34. Torbjorner A, Karlsson S, Odman PA. Survival rate and failure characteristics for two post designs. J Prosthet Dent 1995; 73: 439-444.

35. Standlee J P, Caputo A A, Collard E W, Pollack M H. Analysis of stress distribution by endodontic posts. Oral Surg 1972; 33: 952-960.

36. Weine FS, Wax A H, Wencus C S. Retrospective study of tapered smooth post systems in place for 10 years or more. J Endodont 1991; 17: 293-297.

37. Creugers N H J, Mentink A G B, Kayser A F. An analysis of durability data on post and core restorations. J Dent 1993; 21: 281-284.

38. Deutsch A S, Cavallari J, Musikant B L, et al. Root fracture and the design of prefabricated posts. J Prosthet Dent 1985; 53: 637-640.

39. Cohen B I, Musikant B L, Deutsch A S. A 10-year literature review of a split-shanked threaded post. Compend Cont Educ Dent 1995: 16: 630-631.

40. Saunders W P, Saunders E M. Coronal leakage as a cause of failure in root-canal therapy: a review. Endod Dent Traumatol 1994; 10: 105-108.

41. Tjan A H L, Nemetz $\mathrm{H}$. Effect of eugenol-containing endodontic sealer on retention of prefabricated posts luted with adhesive composite resin cement. Quintessence Int 1992; 23: 839-844.

42. Haddix J E, Mattison G D, Shulmann C A et al. Post preparation techniques and their effect on the apical seal. J Prosth Dent 1990; 64: 515-519.

43. Fox K, Gutteridge D L. An in vitro study of coronal microleakage in root-canal-treated teeth restored by the post and core technique. Int Endod J 1997; 30: 361-368.

44. Ferrari M, Vichi A, Mannocci F, Mason PN. Retrospective study of the performance of fiber posts. Amer J Dent 2000; 13 (special issue): 9B-13B.

45. Nayyar A, Walton R E, Leonard L A. An amalgam coronalradicular dowel and core technique for endodontically treated posterior teeth. J Pros Dent 1980; 43: 511-515.

46. Saupe W A, Gluskin A H, Radke R A. A comparative study of fracture resistance between morphologic dowel and cores and a resin-reinforced dowel system in the intraradicular restoration of structurally compromised roots. Quintessence Int 1996 ; 27: 483-491. 